\title{
S30-04
}

\section{COMPULSORY HOSPITALIZATION, INVOLUNTARY TREATMENT AND GUARDIANSHIP IN CZECH REPUBLIC}

P. Mohr ${ }^{1}$, I. Tuma ${ }^{2}$

${ }^{1}$ Psychiatry, Prague Psychiatric Center, Prague, ${ }^{2}$ Psychiatry, Charles University in Prague, Teaching Hospital, Hradec Kralove, Czech Republic

The Czech law related to compulsory hospitalization dates back to 1966, but it has been revised several times. Besides having mental illness as a criterion for compulsory admission, the law requires the criterion that the patient may only be committed to the hospital, if he is an acute danger to himself and/or others. The Czech law does not accept the criterion that patient may be committed, if there is a danger to his health or if his behavior is not accepted to the community. The law does not specify the type of psychiatric illness required for a person to be committed. A patient admitted voluntarily to a psychiatric ward can be subsequently detained if he fulfilled the criteria of the law. The psychiatrist must examine the patient, decide and apply for commitment. The court has to be notified of compulsory admission in period of 24 hours. The detention is decided by judge in seven days. The detention could last up to 3 months then should be reevaluated by court. Appeals or complaints regarding compulsory acts are referred to the court by guardian or patient himself. A competence proceeding and the appointment of a guardian is considered in the case of demented, retarded, and in some cases of psychotic people. At issue is whether such people are capable of managing their own affairs, to make sound judgment-to weigh, to reason, and to make reasonable decision. Incompetence is decided by judge. Expert psychiatric witnesses play a role in determining the level of incompetence. The court appoints a guardian. 